that the space at our disposal will not permit of our following the author in these interesting discussions, and we can only, in conclusion, heartily recommend the work to the traveller as being admirably adapted to guide him in investigating the geology of a district of extreme interest and great complexity, and to the student at home as containing numerous facts and suggestions worthy of the most thoughtful consideration.

J. W. J.

\section{HEALTH PRIMERS}

Health Primers. Eaited by J. Langdon Down, M.D., F.R.C.P., Henry Power, M.B., F.R.C.S., J. MortimerGranville, M.D., John Tweedy, F.R.C.S. (London: Hardwicke and Bogue.)

THE proverb that a little knowledge is a dangerous 1 thing is especially true in regard to matters connected with health, and it might therefore be supposed that the issue of a series of health primers was a thing to be deprecated, as likely to do harm. But a little reflection will show that this series is intended, not to impart a little knowledge, but to replace the knowledge, not merely .little, but confused and inaccurate, which every man supposes himself to possess, by something more definite and exact. Every one fancies that he knows the appearances of health and disease, and that he is able to decide upon the condition of those whom he daily meets. Every man supposes himself able to ppronounce that such and such a house cannot be healthy, and believes that he is quite capable of judging for himself how much exercise he ought to take, whether he should or should not use a cold bath in the morning, and what is the proper allow ance of beer, wine, or spirits, either for himself or for his neighbours. Now, despite the confidence with which most men will pronounce an opinion on all these subjects, the data on which they would found that opinion would really be very slight, and their knowledge of the subject probably very imperfect and inaccurate, and, consequently, the conclusions at which they would arrive would most likely be erroneous. It is just on such sub. jects as those we have mentioned that the books of this series afford accurate information. The first of them, "On Premature Death, its Promotion and Prevention," is of a less popular character than the others, and has, we think, suffered in consequence of its author not having seen the contents of the other primers. While the material it contains is very valuable, it deals, we think, too much with statistics and too little with the causes of premature death which are under the control of the individual, although occasionally, however, it gives these also, as at p. 46, where ventilation in a hospital is said to have put a stop to the convulsions from which the children died in great numbers, and reduced the mortality to $\frac{3}{6} 5$ of its previous amount. But on the other hand, while we learn that 6 per cent. of the total mortality from all causes is due to diseases of the heart, the writer says nothing of the dangers incurred in running after an omnibus or in trying to catch a train.

The primer on "Personal Appearance in Health and Disease" includes the changes which the body may undergo in the form and size of its bony framework, fatty layer, and internal organs, as well as external colour. These are given shortly and well, though the alterations produced artificially by tight-lacing and high-heeled and tight boots might have been still more strongly insisted upon and emphasised by woodcuts showing their results.

"The House and its Surroundings" is clearly written, and contains a great deal of very useful information. By its aid the householder should be able to know where to look for defects in drainage, ventilation, water supply, \&c., and thus to ayoid many sources of disease, although we think that the dangers of arsenical wall-papers ought perhaps to have been more strongly insisted upon.

"Baths and Bathing" discusses the physiological action, varieties, and uses of baths and bathing localities, both at home and abroad. It is written in a very readable style, and contains both advice as to the use of baths and cautions in regard to their abuse. The author warns against the too heroic use of a morning tub, but forgets to state how very much the chilliness which it brings on in persons of languid circulation may be prevented by using a bath sheet instead of a towel, so that the whole body shall be covered during drying, and not chilled by the exposure of the wet skin to the cold air.

"Exercise and Training" gives a general account of the changes produced in the body by muscular exertion, of the food required, the general régime to be pursued, and the dangers to be avoided. It is evidently written by one who is familiar with the subject of which he is treating.

"Alcohol, its Use and Abuse," deals with a very diffcult subject, and does it well. The author is not prejudiced either for or against alcohol, and maintains that because ninety-nine persons out of a hundred misuse it, it is none the less true that it has a right use, this use being sometimes to check the current of thought and care, as well as to stimulate digestion and circulation, although in perfect health its use is unnecessary.

The purpose which these primers are intended to serve is a very important one, and we think that they are well calculated to serve their purpose. We have pointed out one or two things in which we think they might be improved in future editions, but on the whole they are well and carefully done, giving accurate information in a condensed yet popular form.

T. L. B.

\section{LETTERS TO THE EDITOR}

[The Editor does not hold himself responsible for opinions expressed by his correspondents. Neither can he undertake to return, or to correspond with the writers of, rejected manuscripts. No notice is taken of anonymous communications.

[The Editor urgently requesls correspondents to keep their letters as short as possible. The pressure on his space is so great that it is impossible otherwise to ensure the appearance even of communications containing interesting and novel facts.]

The Mechanical Theory of Earth-Heat

Noticing the assertion made in NATURE, vol. xx. p. 22, in reference to Prof. Church's article in Silliman's Fournal on the Comstock Lode, that "the rock in the lower levels seems to have a pretty uniform temperature of $130^{\circ} \mathrm{F}$.," and remembering what Prof. G. F. Barker, of the University of Pennsylvania, told me, that on a recent visit to those mines he found that there was no uniform temperature, but on the contrary, the most remarkable differences, some of the higher levels being much hotter than some of the lower levels-so that he came to two conclusions:-(I) That the heat was a hot water heat, and (2) that the hot waters were heated mechanically by those continuous movements of the country, so plainly shown both in the mines and at the surface; - it occurs to me to ask the following question :- 